Association for Information Systems AIS Electronic Library (AISeL)

ECIS 2014 Proceedings

\title{
VALUE IN THE MASH: EXPLORING THE BENEFITS, BARRIERS AND ENABLERS OF OPEN DATA APPS
}

Jocelyn Cranefield

Victoria University of Wellington, Wellington, New Zealand, jocelyn.cranefield@vuw.ac.nz

Oliver Robertson

Victoria University of Wellington, Wellington, New Zealand, oliver.robertson@vuw.ac.nz

Gillian Oliver

Victoria University of Wellington, Wellington, New Zealand, gillian.oliver@vuw.ac.nz

Follow this and additional works at: http://aisel.aisnet.org/ecis2014

Jocelyn Cranefield, Oliver Robertson, and Gillian Oliver, 2014, "VALUE IN THE MASH: EXPLORING THE BENEFITS, BARRIERS AND ENABLERS OF OPEN DATA APPS", Proceedings of the European Conference on Information Systems (ECIS) 2014, Tel Aviv, Israel, June 9-11, 2014, ISBN 978-0-9915567-0-0

http://aisel.aisnet.org/ecis2014/proceedings/track23/6

This material is brought to you by the European Conference on Information Systems (ECIS) at AIS Electronic Library (AISeL). It has been accepted for inclusion in ECIS 2014 Proceedings by an authorized administrator of AIS Electronic Library (AISeL). For more information, please contact elibrary@aisnet.org. 


\title{
VALUE IN THE MASH: EXPLORING THE BENEFITS, BARRIERS AND ENABLERS OF OPEN DATA APPS
}

\author{
Complete Research
}

Cranefield, Jocelyn, Victoria University of Wellington, Wellington, New Zealand, Jocelyn.cranefield@vuw.ac.nz

Robertson, Oliver, Victoria University of Wellington, Wellington, New Zealand

Oliver, Gillian, Victoria University of Wellington, Wellington, New Zealand

\begin{abstract}
The open government paradigm relies on the provision and reuse of open government data (OGD) to improve transparency and create new sources of value. This study aims to progress understanding of $O G D$ beyond a theoretical commentary by exploring the perceived sources of value of mashups (online services that combine diverse OGD), and to examine issues that impact on, and facilitate, the delivery of this value from an 'insider' perspective. Based on open-ended interviews with 17 individuals actively involved in OGD application design, use, and advocacy in New Zealand (ranked fourth in the 2013 Global Open Data Barometer) nine key sources of value were identified: Ease of discovery, improved data quality, bringing knowledge into relevant contexts, economic benefits, social benefits, cost reduction and efficiencies, predictive value, transparency, and ability to explore and play. Twelve barriers to delivering this value were found, ranging from change-related issues to problems relating to sustainability. Six facilitators were identified as helping to overcome these barriers and realise the value of $O G D$.
\end{abstract}

Keywords: open data, mashup, open government, value creation 


\section{Introduction}

Open government data (OGD) is a foundational element in the emerging open government paradigm. By releasing high value data sets in open formats and under open copyright licenses, governments are seen as enabling citizens to more readily access and use this data. Furthermore, by combining OGD sets with each other and/or additional data in novel ways, those who reuse OGD can potentially empower citizens and create new sources of value for society and the economy (Maali, Cyganiak, and Peristeras, 2010). The OGD model of government-citizen interaction is therefore seen as having advantages over government's traditional role of providing services (Yildiz, 2007) and processed information (Robinson, Yu, Zeller, and Felten, 2009). However, the provision and use of OGD is still in its infancy, so the purported benefits although much spoken about are largely unsubstantiated. The fact that New Zealand was ranked fourth in the 2013 Global Open Data Barometer indicates that New Zealand could be considered a leader in the OGD movement. This international standing contributes to our motivation to probe beyond the government rhetoric promoting OGD. Our study aimed to generate a richer understanding of the sources of value of OGD, and to identify key barriers to, and enablers of, the delivery of this value, based on the perceptions and experiences of active participants in New Zealand's emergent open data community.

The specific objective of this study was to elicit the perspective of those actively involved in the New Zealand OGD community on the delivery of OGD value, which we refer to as the insider perspective'. This paper begins by synthesising themes about the value of OGD from the literature. It then outlines the research method before reporting and discussing findings. Based on interviews with seventeen individuals in diverse OGD roles we identify the perceived sources of value from the use of OGD in 'mashups', as well as the key barriers to, and facilitators of, OGD value delivery in this context.

\section{Literature review}

Government provision of information has historically been important in informing citizens and allowing access to needed information. Early e-government initiatives introduced the possibility of sharing information between government entities (Zhang et al. 2005). Recently there has been a shift towards government being an open data provider, making diverse government data sets publicly available (Brito, 2007). This emerging role is seen as creating potential new benefits for the private, public and government spheres (Maali et al. 2010). The Open Data Barometer report (Davis 2013b) summarises the promise of OGD in four categories: more efficient and effective government, innovation for economic growth, transparency and accountability, and inclusion and empowerment. It notes that, "these potential outcomes provide a strong argument in favour of shifting to 'open by default' for all the non-personal data governments collect. Right now, much of the value of government held data remains locked-up" (p.10).

Transparency is seen as a key benefit of OGD (Bertot, Jaeger, and Grimes, 2010; Janssen, Charalabidis and Zuiderwijk, 2012; Ruppert, 2013). Through the ability to access and explore open data, citizens are seen as having improved opportunities to participate with, understand and critique the actions of their government (Chun, Shulman, Sandoval, and Hovy, 2010; Machado and Parente de Oliveira, 2011). Allowing citizens to access data sources and perform analyses may thereby strengthen trust in government (Lebo et al., 2011; Wakaruk, 2013). The increased examination can shed light on potential waste and act as a strong incentive against corruption (Brito, 2007; Piotrowski and Borry, 2010). Many governments are now acknowledging the importance of open data and the role it can play in increasing transparency and public trust (LINZ, 2009, 2013; Obama, 2009). However, there is some 
incompatibility between a security focused perception of e-government and the ideals of transparency (Coglianese, 2009; Halchin, 2004), requiring decisions as to what data should be made public and what data must be protected (Chun et al., 2010; Ohm, 2010). Some authors have pointed out that transparency and open data are not inherently positive; they can also be used as political tools working for particular agendas (Bates, 2012) and may disempower those individuals whose stories are not captured in the data and those who lack the capability to conduct arguments through datasets (Davies, 2013a, p.23).

OGD is also seen as providing potential social and economic benefits to government and the public, allowing the data to inform dialogue on important social and economic issues (Lathrop and Ruma, 2010). E-government systems are already lowering government costs (Titah and Barki, 2006), and opening up more government data has the potential to significantly further lower costs and add economic value by making data discoverable and available to those who need it at marginal cost (Alonso et al., 2009; LINZ, 2009). In addition, timely, accurate and relevant information is seen as essential for the effective functioning of markets (Stiglitz, 2000).

However, the promise of the benefits of open data could also be regarded as more hype than substance. The gaps between promise and reality have been characterised as myths (Janssen, Charalabidis and Zuiderwijk, 2012) or empty rhetoric. Furthermore, the extent of change required to internal organisational processes (Conradie and Choenni, 2012) may not be taken into account.

As raw data is not meaningful to most end users, open data does not automatically create value. The creation of value from OGD requires conceptual and technical skills. It is therefore through the products and services of skilled intermediaries, people who synthesise content by combining data and information from diverse sources in new ways (Beemer and Gregg, 2009) that the average citizen will get most value from open data (Bertot et al., 2010; Hood and Heald, 2006). Nations therefore rely on intermediaries to create value for citizens via OGD apps, mashups, representations, and analyses.

Mashups reuse and combine data from more than one source to create a new service and user experience (Koschmider, Torres, and Pelechano, 2009; Sieber and Rahemtulla, 2010). They are seen as an important value-delivery vehicle for OGD, translating raw data into useful information and thereby "bringing out the full potential of open government data" (DiFranzo et al., 2011, p. 206). They may create innovative new services and/or present data in new and unforeseen ways (Beemer and Gregg, 2009; Salminen, Kallio, and Mikkonen, 2011; Wakaruk, 2013). Value may be created by providing context and meaning that is relevant to the individual user (DiFranzo et al., 2011). At a technical level, a mashup is a "lightweight, Web-based, composite application[s], with no native data store or content repository" (Gartner, 2013). OGD mashups are typically end-user driven, created for personal or general use by citizens to help find information, provide a service, and/or to allow the examination of once-separate data sets in context (Grammel and Storey, 2008; Lathrop and Ruma, 2010). The ideal is that users with no particular programming skills can take disparate data that is of interest to them, and recombine it in their web browser (Albinola, Baresi, Carcano, and Guinea, 2009). However, this may be more myth than reality: Zang, Rosson, and Nasser (2008) argue that a high level of technical skills may be required to leverage the relevant technology. Enterprise mashups combine data and services belonging to private enterprises with public domain data and services (Stecca and Maresca, 2010) to create new business value and solve existing or ad-hoc business problems (Hoyer and Stanoevska-Slabeva, 2009). Geospatial mashups provide the ability to view multiple data sets or data streams in a consistent geospatial context (Gartner, 2013).

While the opening of government data has led to many new datasets becoming available, Yang and Kankanhalli (2013) note a surprising lack of external stakeholders making innovative uses of this data. This could perhaps be due to the technological barriers previously mentioned, or a lack of interested citizens wishing to engage (Harrison, 2013). However, other commentators have pointed out diverse interesting and innovative uses of OGD (Brito, 2007; Lathrop and Ruma, 2010; Robinson et al., 2009). It is notable that most of these are applications, mashups or sites that are focused on creating social 
goods. Lacking in the literature is an exploration of how individuals or businesses are using open data to create new applications or mashups with a sustainable commercial outcome. Tied into this is the difficulty in measuring the economic impact of opening government data in general (Huijboom and Van den Broek, 2011). Sustainability of OGD value appears to be a critical issue for future research.

The literature identifies many barriers that are slowing or stopping the adoption of open government data (Chang and Kannan, 2008). A government's philosophy towards opening their data and the initiatives they undertake are often embedded within a particular policy framework (Bertot and Choi, 2013). Politicians and bureaucrats may view opening data as a threat, with the potential to reduce their power (Wakaruk, 2013) or illuminate waste or corruption in a damaging way (Brito, 2007). While central government initiatives are one of the major drivers behind opening data, realising OGD value also requires the acceptance and support of all collaborators involved (Gomes and Sousa, 2012). Even with the policy mandate to open data, change within a government organisation can be slow, requiring widespread cultural changes (Bertot et al., 2010) and a shift to an open system of governance (Janssen, Charalabidis and Zuiderwijk, 2012). Although long term cost reductions may arise from opening government data, there can also be large upfront costs in setting up the required systems and practices (Titah and Barki, 2006). There is also the potential for misuse or misrepresentation of government data, and some users may want unmediated data (Robinson et al., 2009).

The literature notes a number of drivers that are helping overcome the barriers to open government data. Private actors have been important drivers behind opening up government data, helping to overcome barriers by manually extracting data and illustrating the value that could be added if it was freely available (DiFranzo et al., 2011; Robinson et al., 2009). These efforts make the data available to the public, but are often inefficient and inexact. Opening this data would remove errors and reduce the costs of those producing sites (Brito, 2007). Conferences, hackathons and other programs to spread awareness of open data can also work to increase usage and thus encourage governments to open more data (Huijboom and Van den Broek, 2011). The importance of developing strategic partnerships with end-users has also been identified (van Veenstra and van den Broek, 2013). However, understanding how to address the barriers to delivering OGD value remains at an early stage and there is a need to build better insights based on users' perspectives (Janssen, Charalabidis and Zuiderwijk, 2012).

\section{Method}

The aim of our study was to better understand how applications and mashups of OGD can create value for citizens and government by examining the views of a community of early OGD users. Specifically, we aimed to investigate what challenges are associated with the somewhat abstract set of ideals put forward in the literature, and to understand the facilitators of OGD value delivery. As the use of OGD is still at an early stage, we aimed to elicit the insider perspective, a view from inside the OGD community, by undertaking an interpretivist study of early OGD adopters and champions. According to interpretivism, reality is subjective product that is constructed by people and informed by their values and beliefs (Myers, 1997; Orlikowski and Baroudi, 1991). Research in this tradition seeks to understand the meanings people assign to phenomena rather than uncover an independent reality. This approach was suitable given the small OGD user population in New Zealand, as interpretivism makes no presumption about 'neutrality'. While the pool of people we could draw on would inevitably have positive beliefs about OGD, our goal was to understand the views of those with hands-on experience, rather than seek alternative or complementary views. The involvement of early adopters in studies has a long history and can be seen as valuable in the case of an emerging paradigm, such as open government.

We used qualitative methods, conducting semi-structured, open-ended interviews of 45-60 minutes with individuals who were involved in the development and use of OGD in the context of mashups 
that include a geospatial component. The open data community in New Zealand is small, and by restricting the scope we were able to focus on an area of common practical experience (geospatial data has been available for some time in New Zealand and is incorporated in many mashups). This allowed us to make effective use of snowball sampling, identifying a range of individuals with relevant experience and different roles. Our specific concentration on mashups enabled a clear focus on the value proposition and the inherent need for conceptual and technical skills.

We first contacted individuals within government and the private sector who were known figures in the OGD movement. We spoke with them to gain a better understanding of the movement, identify promising applications/mashups, and locate others who may have valuable opinions. We also posted on two OGD-related mailing lists requesting interviews with people involved with OGD. We planned to interview people from government, people involved with pro-open data movements, such as Open New Zealand and the 'open government ninjas' (members of an open data developer community that has been active for many years in encouraging the NZ government to adopt open data policies), heavy data users, such as researchers, academics and geospatial information systems (GIS) technicians; developers of OGD mashups, and end-users of OGD applications. While individuals were happy to provide introductions to other developers or professionals in the area, those with access to end-users cited barriers to connecting us with members of this small population. This was, to some extent, compensated for by the fact that developers and open data advocates were themselves users of OGD applications, so could represent (skilled) user perspectives. The resulting pool of participants consisted of 17 individuals, some of whom had multiple roles in relationship to OGD. Their roles included private sector users and developer-users (8), technically oriented OGD evangelists (known in the OGD community as 'ninjas') (4), government-based OGD advocates, policy developers, providers and users (8) and an NGO-based user/advocate (1). Profiles of the interviewees are shown in Table 1.

\begin{tabular}{|l|l|}
\hline Aidan & Private sector developer/user \\
\hline Ben & Private sector user (GIS specialist) \\
\hline Cameron & Private sector developer/user \\
\hline Dean & Private sector ninja/user \\
\hline Erick & Private sector ninja/developer, \\
\hline Francine & Government advocate/policy-maker \\
\hline Greg & Private sector developer/ninja \\
\hline Hannah & Government advocate/facilitator \\
\hline Irene & Government sector developer/user (GIS specialist) \\
\hline Jared & Government advocate/policy-maker \\
\hline Ken & Private sector developer/user \\
\hline Lisa & Private sector developer/user \\
\hline Martin & Government advocate/policy-maker \\
\hline Nelly & Government advocate/OGD provider \\
\hline Owen & Government provider \\
\hline Pat & Government provider \\
\hline Quintin & NGO-based user/advocate \\
\hline
\end{tabular}

Table 1. Pseudonyms and roles of interviewees.

We transcribed the interviews then, using qualitative data analysis techniques, coded and analysed the transcripts in NVivo. In addition, we applied the same coding approach to the academic literature. This allowed us to identify reoccurring and divergent themes within and across groups, and compare the ideals and goals of the individuals interviewed with the benefits identified in the literature. (We did not, however, prompt our interviewees with themes from the literature.) The codes assigned to the 
transcripts were categorised as follows: ideals, sources of value, barriers to OGD, the kinds of knowledge created, and ways in which the delivery of OGD value was being facilitated.

After completion of this primary data collecting stage we interviewed two further individuals to clarify and extend our understanding of issues in some areas. We also created a Wordpress site, summarising results from the interviews, and invited those who we had spoken with to give us anonymous feedback. This served to corroborate and fine-tune our results, and provided additional data.

\section{Findings}

\subsection{Value creation}

Nine main categories of value creation emerged from the analysis of the interview data. Unsurprisingly, many of these themes reflected the ideals from the literature. We summarise the key sources of value that were identified in the interviews below, then discuss some variances in the perspectives and emphases of those in public versus private sector roles.

Ease of discovery: Applications that take government data and present it in a new way were seen as making it much easier for users to discover and access the data. The raw data sets can be hard to find and navigate, and OGD users said that many applications help users to find the information they need.

Improved data quality: Opening data was seen as leading to improved data quality via crowdsourcing of corrections or by filling gaps in data (for example, geocoding historical photos).

Generating contextually relevant knowledge: Many applications allow users to see information that is useful for them, tailored to their needs or locations. Combining OGD with other data sets and smart phones allows users to access data that is relevant to their current situation and geographical position.

Economic benefits: Opening government data is believed to bring a range of economic benefits. Hannah, for instance, commented on the likely motivators for action: "I think it was predominately the social and economic outcomes and encouraging the marketplace to develop products and services which increase productivity, offer employment, provide revenue back to government in the form of taxation revenue" Some of these economic benefits are measureable but many more are hard to see and measure. Several individuals reported that opening government data had allowed them to explore new business opportunities.

Social benefits: People reported that open data had the potential to allow individuals to interact with government in a more informed and interactive manner. Applications such as Campermate, which gives campers local information, and FixMyStreet, which publishes and routes reports of street-related problems to relevant local authorities, illustrate the early social benefits of open data.

Cost reduction and efficiencies: Some individuals reported that opening government data significantly reduced the costs associated with acquiring data. Previously, sourcing data had significant costs in both time and money. This creates new efficiencies and ties in with the economic benefits. More general efficiencies in government operation were also noted. Not all interviewees though were convinced by these claims: Jared noted, "I'm personally a little bit sceptical that that's the case, I mean if it is I think it will be minimal and trivial".

Predictive value: By combining and analysing government data, individuals and organisations were seen as being able to make more accurate predictions about the future and thus improve decisions. For example, the ANZ bank's Truckometer uses heavy traffic data to successfully predict GDP trends.

Transparency: Making government data transparent should increase public trust in government and civil servants. Many people said that while corruption is not currently a problem in New Zealand, the transparency that open data brings may reduce the likelihood of it happening in the future. 
Ability to explore and play: Opening government data was seen as encouraging developers and the general public to explore and play with new data. This is a theme that did not occur in the literature. Participants noted that playful exploration allows people to discover new interactions within, or uses for government data that may be outside the scope of the department that released it.

The most commonly cited benefits by those who worked in government were economic. While the majority of participants firmly believed in these benefits, they also noted that currently there are not many visible manifestations of them. There are few applications using government data with sustainable business models, and many of the benefits are widely dispersed and hard to see. Some individuals noted that they had received good feedback from agencies, and that a cultural change is underway that will take time to build momentum. Francine noted, "That's the mighty cultural shift or the cultural wall we always talk about - which is changing the minds of the middle managers everywhere". The literature also emphasizes the importance of cultural change in government as a driver (Bertot et al., 2010). Many individuals from government also emphasized the potential benefits arising from increased research and knowledge growth. According to Dean, OGD has "allowed universities to train their students much, much better and that's...the sort of data they'll have when they hit the private sector or when they get a job in government". Such benefits are much harder to track than direct economic effects, but may have a large long-term impact on the economy.

We split the private sector participants into two main overlapping groups; data users, such as academics, researchers and GIS technicians, and open data advocates such as the ninjas; developers who use the data to create applications and mashups and end users. The ninjas were founded by members of Open New Zealand, and helped to start the OGD movement in New Zealand. They emphasized the efficiency gains that are possible with open data, the increased transparency of government processes and the ability of individuals to use the data in new or creative ways to create economic or social value for themselves and other citizens. Many data advocates were also developers. Erick, one of the primary private individuals who worked to open data, was motivated by possible increased efficiencies and his desire to create applications that use the data, whereas Greg, another open data advocate, approached OGD with more of an emphasis on transparency and public good. This could be seen in the applications and services he had created with a civic focus: "People like myself... have come at it from probably a more civic point of view...it's a public good to have better transparency or to be able to do things more efficiently".

\subsection{Barriers to value creation}

Participants identified twelve different barriers that serve to stop, slow or reduce the benefits from open data in New Zealand. Barriers were seen as occurring on both the government and private sides of the equation, but with some impacting more on one sector or the other.

Resistant individuals: Individuals within an organisation are seen as having a huge effect on that organisation's open data approach. Depending on their views, individuals may act in ways that either help open their organisation's data efforts or significantly slow its progress. As Irene reported,

"there's an organisation... [that] has set their data very much based on an individual's understanding of privacy concerns. And they've pretty much shut everybody down". Individuals can also work to open up data within an organisation, then "subsequent to them moving on its blown wide open.... individuals within organisations can have a huge impact on what the actual policies are" (Irene). Some individuals who have worked with a culture of user pays and closed data reportedly do not see the benefit of opening their data. Also, without a higher-level mandate to open data, an individual is taking on a potentially significant level of risk if something goes wrong due to a decision they made.

Cost of opening up data: Time and resource costs were seen as major obstacles for government departments in opening their data, especially as they were often experienced as upfront costs. 
Releasing and sustaining a supply of data was also seen as an ongoing commitment in terms of staff time and money. Without increased budgets, moves within an agency to open data for reuse in a computer readable format require reassigning resources. Prior to releasing data, costs are unknown, new procedures and systems need to be established for processing and supplying data, and the benefits are unknown. To push open data, the people within an organisation were seen as needing incentives, either from someone in a position of authority, or from the belief that the value it will generate would exceed the risks and costs.

Loss of old income/business model: Many government entities have previously sold their data. While releasing it may provide many widespread social benefits, these are hard to measure and will show up as less revenue on their balance sheets without a corresponding measureable increase in services. Organisations that currently have a model based on selling their data are incentivised to keep doing so, working against the OGD ethos. Some crown entities, such as the Historic Places Trust and some Crown Research Institutes have had selling and profiting from data built into their mandates. Even when the data acquisition or research is performed with taxpayer funds there may be an expectation of earning returns from it. Ben reported that "they create this data for research from public and then they kind of sell that back". Some councils have historically taken the view that they can sell it to generate income. This idea persists, even though many outside of these agencies believe it is a flawed model. Dean commented that some "councils delude themselves into thinking they can sell their data. They never have, but they continue to delude themselves". It appears that this is starting to change but there hasn't been a wide cultural shift yet. Even minimal income from sales can make councils or organisations loath to open their data: Sales are a positive on their balance sheet while the benefits of open data are more diffuse and hard to measure.

Data ownership legacy issues: In the past, if councils or government departments contracted a third party to gather data for them, or purchased data directly from the third party, they often licensed the data and did not own the intellectual property rights, and thus could not directly release it under open copyright. Respondents reported that while this is changing, it is still an issue that affects some data sets and organisations.

Invisibility of benefits: While some of the benefits of open data were seen as being clear and measureable, a great many more of the potential benefits were seen as being opaque and hard to measure. This issue reportedly makes it more difficult for government departments to justify investing adequate resources in opening their data and improving their data supply.

Reduced stakeholder feedback: Making the data acquisition process as easy as possible aids in the acquisition and use of OGD but some participants noted that this also reduces the feedback received by government agencies about the usefulness of data. The lack of a detailed audit trail makes it harder to know what data people value/need, what they should change in the future, and whether their releases are really providing a tangible benefit.

Uncertainty about data stream continuity: If a user is not positive that a data stream will be maintained in the future, this creates uncertainty around any project using that data stream. This reduces the chances that a company or individual will be willing to invest the time and resources into a product or application that uses this data. As Dean commented, "you'd be a very foolish company really to go and build a business model on an open data service that has no longevity guaranteed". 
Lack of sustainable OGD business models: The market for New Zealand centric applications is small, making it difficult to build sustainable businesses around OGD. Individuals have created interesting and useful applications that use open government data, but creating an application or finding a new use for open data is costly. Developers need to invest time and resources into finding uses for and ways of displaying data, then developing the actual application. Even if an application is useful to many people it will not necessarily generate income. The lack of a revenue stream means that people cannot devote as much time as they would like to development. In the absence of a revenue stream, compensatory incentives were seen as necessary.

Difficulty of discovery/access: Participants noted that it can be hard for developers-users to find the data they need. While data that is hosted on services (e.g. Koordinates and data.govt.nz) is easy to find and use, those government agencies that are not required to release their data may not use these services. Users emphasised that it is essential to make open data easy to find and access in order for it to be useful.

Concerns about data quality: Participants reported that government departments may be reluctant to release data that they see as low quality. Some agencies are worried about the potential liabilities of releasing their data; for example, prior to releasing its data, one government department had reportedly been concerned that people could potentially injure themselves outdoors, or get lost. Also, users require a level of quality in OGD in order for them to be able to use it to create mashups/applications.

Privacy: Some interviewees reported that when departments collect data that includes private or potentially sensitive information on citizens, there can be concerns over whether and how the data can be anonymised, what can be released, to whom and under what copyright. Complying with privacy legislation appears to be seen as involving complexity and risk.

Copyright issues: In order for government to share data, and for private developers to create applications that use it, there needs to be a system of open copyright. The New Zealand Government Open Access and Licensing (NZGOAL) framework mandates the use of the creative commons license (for government departments and a group of agencies) where possible to allow the free reuse of data. Even so there are some copyright barriers. Data collected prior to the implementation of NZGOAL by government agencies and more recent data acquisitions by councils may, if the data was purchased from a private third party, allow use only by the purchasing organisation, leaving ownership of the intellectual property with the third party. This reduces costs in the short term but prevents government from releasing the data for reuse.

\subsection{Facilitators of value creation}

Participants identified a range of factors, including activities, resources, people, and public-private sector partnerships, which in combination are facilitating New Zealand's delivery of value from OGD, helping to promote and smooth its uptake, and incentivising innovation. At a high level, uptake has been facilitated by the 2011 Declaration on Open and Transparent Government, committing agencies to releasing OGD, the NZGOAL framework, and related leadership and evangelism. Those working in government reported facilitators focused on incentivising application development and identifying useful, interesting cases of OGD-based applications to act as exemplars. A set of case studies had been developed to demonstrate the diverse nature of emerging OGD value, provide feedback to early users, and to raise awareness and create interest and demand in the private sector; while intermediary portals and sites were increasing the visibility, accessibility and ease of use of data sets. Recently appointed data champions had successfully played activist role within government, while open data ninjas had played a key role in promoting OGD at a national level and to developers. These facilitators were together seen as increasing adoption and use by the public and private sectors, and end users, and as 
better articulating and increasing the visibility of value to suppliers and users. Many participants emphasised a need for creative new initiatives to incentivise and sustain OGD use at a structural level; and a particular need to focus on supporting OGD start-ups, business model creation, and developing means that address sustainability concerns.

Government policy: The 2011 Declaration on Open and Transparent Government, requiring departments to make their high value data available for use and reuse has been one of the main drivers in opening government data. Respondents reported that since this policy was instituted much more data had been made available, but that there was still a long way to go.

People: As noted earlier, individuals were found to play key roles in facilitating (or hindering) the value of data from OGD. Our interviews highlighted two key groups of people within which individuals had played important facilitating roles: The ninjas are a group of technically skilled evangelists and users. Their mailing list serves as a place for people interested in open data to communicate, talk about potential problems and solutions, and provides a space where individuals within government can speak to interested, informed private citizens. Other open data advocates: Other individuals, both within and outside of government, were reported to have had a huge positive effect on opening government data in New Zealand. Originally relying on those with personal passions, advocate roles have recently become more formalised, with appointed Data Champions in government agencies. Many individuals in the private sector have also campaigned to open data. It was often reported that it takes individuals within an organisation to drive change, and that the organisations that have opened up the most have benefitted strongly from individuals who believed in open data. Our participants were reluctant to blow their own trumpets, and there is an opportunity to better explore the role of individuals and networks of individuals as facilitators, activists and change agents in the OGD space.

Portals and intermediaries: Participants noted two sites that played a key role as intermediaries. Data.govt.nz allows ready discovery and access to government data sets, and facilitates requests for other data sets of interest. Its use provides government departments with feedback on what is useful and what can be improved. Koordinates.com allows users to search for, sort, bookmark, access and share geographic data sets. Its website states that is has 7000 users from 100 countries, and it has partnered with Land Information New Zealand to make data more available and accessible.

Case studies and exemplars: Case studies (available at ICT.govt.nz site) have been developed and are being actively used to demonstrate to government departments and other organisations the value and potential benefits of opening their data, giving insight into possible business models. The case studies include examples of Apps, Agency Releases, and reuse by Statistics NZ.

Kickstarter incentives: For open data to be useful, it must be accessible and citizens and developers need to know that it is available. A government-sponsored Mix and Mash competition has helped on both fronts. The promotion and prizes let people know what data is available and create incentives to explore it. Seeing the results encourages government departments to release more data.

Public/private partnerships: Several participants reported that Private/public partnerships help create incentives for people to create applications that use the freely available data. Financial support from a department allows for the creation of useful applications that utilize the data they are making available. 


\section{$5 \quad$ Discussion}

Our findings make it clear that the degree to which a particular government department or crown entity buys in and adopts open data policies depends on many factors, such as perceived benefit, the individuals within the organisation, public and political pressure and the resources available. At this stage in the movement towards open data most government organisations do not have institutional knowledge of how to make the shift to an OGD mentality supported by effective OGD provision, and supporting values have not been embedded, so there is a strong reliance on key individuals to overcome organisational resistance. In comparison to a set of OGD adoption barriers identified in a 2012 study of managerial and administrative staff by Janssen, Charalabidis and Zuiderwijk, this study identified relatively few legislative and technical barriers, while highlighting the critical role played by individuals within organisations (as barriers or facilitators) and the problem of finding sustainable business models. These differences may arise from a combination of factors, such as New Zealand's legislative environment (NZGOAL is seen as conducive to OGD use - see below), its relatively small potential user population, which may impact on business model design, and the practical focus of this study, arising from both the inclusion of hands-on developers, and business and technical users (who have a good understanding of the relationship of business models and livelihoods to OGD use) and the study's focus on mashups. (The problem of developing business models is also identified by van Veenstra and van den Broek (2013)). 'Gaps' that may appear in comparison with the barriers identified in other studies (and from the literature review) can also be seen as arising from the inductive nature of our study - we did not confront participants with themes from the literature, but encouraged discussion of the issues they saw as most significant.

In order for agencies to fully buy in and effectively operationalize open data policies, the study suggests that there need to be obvious benefits, political pressure, organisational structures in place, and proactive individuals within the organisation who strongly believe in open data. The different structures and layers within government also play a role: New Zealand's NZGOAL Framework provides guidance for government agencies when releasing copyright and non-copyright material.

The existence of the NZGOAL framework in conjunction with existing freedom of information, privacy and public records legislation would have contributed to New Zealand's relatively high ranking in the readiness dimension of the Open Data Barometer survey ${ }^{1}$. The survey also collected data to rank countries in terms of implementation and impact (Web Foundation, 2013). New Zealand's implementation score is similar to that of Australia, Canada, the Netherlands, France and Germany, but slightly lower than that of Norway and Denmark. However, New Zealand's impact score is noticeably higher than that of all the above-mentioned countries, which is intriguing and seems contradictory. The Barometer's use of "claims made in credible sources concerning possible impacts of open data" (Web Foundation, p.37) as a proxy for assessing impact suggests that New Zealand may simply have been more active in publishing and promotion than other countries.

It is a concern that for many (and possibly most) organisations, the benefits of OGD appear to be hard to see, so may rely on the faith and passion of employees. Releasing open data has costs associated with it but the diffuse, hard to measure benefits could well dwarf these costs. The difficulty in measuring the benefits and lack of positive feedback loops could mean that even though the benefits outweigh the costs for the public, when it comes to an individual agency doing a cost benefit analysis they under invest. Francine spoke of an agency that was "one of the primary examples of taking a more permissive approach...they don't make a few million under their specific budget, but the wider economy potentially benefits in massive ways that are much more diffuse and harder to pinpoint".

1 Readiness, implementation and impact scores for each country surveyed are available at https://docs.google.com/spreadsheet/pub?key=0ApqzJROt-jZ0dGxJa3g2Slg0MEhiQU11NkhOZy1GeWc\&output=html 
Some individuals expressed strong concern about the difficulty in creating a sustainable environment for the creation of applications and services that use open government data. The lack of funding and incentives means that even when there is potentially a large public good that could be achieved there is under-investment. The lack of visible benefits is undoubtedly a major barrier to wider adoption of open data policies. The rapid emergence of big data analytics in governments may offer considerable promise in increasing the visibility of value, and revealing unexpected correlations.

\section{Conclusion}

This study has captured the views and experiences of individuals in diverse roles in New Zealand's emergent open data community - advocates, designers, and early adopters of OGD regarding benefits, barriers and facilitators of value from OGD in the context of mashups (application that combine government data sources). While their opinions regarding the potential value of OGD are similar to the ideals in the literature, the study was of value in extending some of these themes and capturing the nuances involved in the delivery of this value. Identifying the nuances is particularly important in the New Zealand context given the emphasis on promotion, which, as noted above, seems to be reflected in the Open Data Barometer impact score. Also, a value not previously identified in the literature emerged from the interview data, namely that opening data provides the ability to explore and play. This is significant, and suggests that further exploration of a relationship between OGD and creativity and innovation would be worthwhile.

The research also extends findings reported in the literature relating to barriers in the depiction of these as being interrelated, thus forming a network that provides a threat or hindrance to the value of open data, and a number of practical solutions that are currently being used to address these barriers and to facilitate committed OGD uptake and value delivery. While some of the issues can be seen as the expected outcomes of organisational change (resistance to change, costs), others, particularly those relating to sustainability are more systemic and remain vexing.

Based on these understandings, there is an opportunity for researchers, government and industry and nations to examine these issues and potential solutions in more depth. Of particular interest is the role of individuals as facilitators and change agents in organisations. Although the OGD movement is relatively new, consideration of initiatives in the context of related experiences seems to be particularly appropriate, given New Zealand's long established freedom of information and public records legislation. A disconnect between internal organisational systems and processes and responses to new information policies may be a characteristic feature of the New Zealand environment, but further research would be required to explore this. In the meantime, relevant findings from this project, such as the importance of taking the broader societal context into account when undertaking cost benefit analysis can be used to raise awareness of implementation challenges.

Cross-country studies are likely to be of value in exploring larger solutions, and could extend to investigating the potential for global level OGD frameworks and business models. The extent to which cultural factors influence implementation of OGD deserves more attention and exploration.

The Open Data Barometer report (Davies 2013), the first global report and survey, notes that, "just because $O G D$ in the abstract is a common ingredient to all these forms of change, that does not necessarily mean that any and all open data help secure any and all outcomes. There will be different datasets and different pre-requisites involved in securing different kinds of open data impact. Meanwhile, across different countries the range of quality of data that is 'locked up' inside government, and the relative costs of getting it out, will vary." (p.10). Our study has sought to examine the delivery of value in one country only, but given that New Zealand is an early OGD leader in the delivery of value (ranked $4^{\text {th }}$ in the Open Data Barometer) it is likely that some of these understandings and solutions are transferable to other contexts. 


\section{References}

Albinola, M., Baresi, L., Carcano, M., and Guinea, S. (2009). Mashlight: a lightweight mashup framework for everyone. Paper presented at the Workshop on Mashups, Enterprise Mashups and Lightweight Composition on the Web.

Alonso, J., Ambur, O., Amutio, M. A., Azañón, O., Bennett, D., Flagg, R., . . . Sheridan, J. (2009). Improving access to government through better use of the web. World Wide Web Consortium.

Bates, J. (2012). "This is what modern deregulation looks like": co-optation and contestation in the shaping of the UK's Open Government Data Initiative. The Journal of Community Informatics, 8(2). Available at http://ci-journal.net/index.php/ciej/article/view/845

Beemer, B., and Gregg, D. (2009). Mashups: a literature review and classification framework. Future Internet, 1(1), 59-87.

Bertot, J. C., and Choi, H. (2013). Big data and e-government: issues, policies, and recommendations. Paper presented at the Proceedings of the 14th Annual International Conference on Digital Government Research.

Bertot, J. C., Jaeger, P. T., and Grimes, J. M. (2010). Using ICTs to create a culture of transparency: E-government and social media as openness and anti-corruption tools for societies. Government Information Quarterly, 27(3), 264-271.

Brito, J. (2007). Hack, mash and peer: Crowdsourcing government transparency.

Chang, A.-M., and Kannan, P. (2008). Leveraging Web 2.0 in government: IBM Center for the Business of Government.

Chun, S. A., Shulman, S., Sandoval, R., and Hovy, E. (2010). Government 2.0: Making connections between citizens, data and government. Information Polity, 15(1), 1-9.

Coglianese, C. (2009). The transparency president? The Obama administration and open government. Governance, 22(4), 529-544.

Conradie, P., \& Choenni, S. (2012, October). Exploring process barriers to release public sector information in local government. In Proceedings of the 6th International Conference on Theory and Practice of Electronic Governance (pp. 5-13). ACM.

Davies, T. (2013a). Transparency and open data. 19-23. Sciencewise expert resource centre. White paper. Available at http://eprints.soton.ac.uk/355269/1/ScienceWise\%20Anthology\%20\%20Chapter\%206.pdf

Davies, T. (2013b). Open Data Barometer 2013 Global Report. Open Data Institute and World Wide Web Foundation. Available at http://www.opendataresearch.org/dl/odb2013/Open-DataBarometer-2013-Global-Report.pdf

DiFranzo, D., Graves, A., Erickson, J. S., Ding, L., Michaelis, J., Lebo, T., Patton, E., Williams, G., Li, X., Zheng, J., Flores, J., McGuiness, D., and Hendeler, J. (2011). The web is my back-end: Creating mashups with linked open government data. In D. Wood (ed.) Linking Government Data, Springer Verlag (2011), 205-224.

Gartner (2013). IT Glossary. http://www.gartner.com/it-glossary

Gomes, R., and Sousa, L. (2012). Contributions to the Development of Local e-Government 2.0. Future Internet, 4(4), 882-899. 
Grammel, L., and Storey, M. A. (2008). An end user perspective on mashup makers. University of Victoria Technical Report DCS-324-IR.

Halchin, L. E. (2004). Electronic government: Government capability and terrorist resource. Government Information Quarterly, 21(4), 406-419.

Harrison, T. (2013). The "audience" as participative, idea generating, decision making citizens: will they transform government?

Hood, C., and Heald, D. (2006). Transparency: The key to better governance? Oxford University Press.

Hoyer, V., and Stanoevska-Slabeva, K. (2009). Towards a reference model for grassroots enterprise mashup environments. Paper presented at the ECIS.

Huijboom, N., and Van den Broek, T. (2011). Open data: an international comparison of strategies. European journal of ePractice, 12(1), 1-13.

Janssen, M., Charalabidis, Y., \& Zuiderwijk, A. (2012). Benefits, adoption barriers and myths of open data and open government. Information Systems Management, 29(4), 258-268.

Koschmider, A., Torres, V., and Pelechano, V. (2009). Elucidating the mashup hype: Definition, challenges, methodical guide and tools for mashups. Paper presented at the Proceedings of the 2nd Workshop on Mashups, Enterprise Mashups and Lightweight Composition on the Web at WWW2009.

Lathrop, D., and Ruma, L. (2010). Open government: Collaboration, transparency, and participation in practice: O'Reilly Media, Inc.

Lebo, T., Erickson, J.S., Ding, L., Graves, A., Williams, G.T., DiFranzo, D., Li, X., Michaelis, J., Zheng, J., Flores, J., Shangguan, Z., McGuinness, D.L., and Hendler, J. Producing and Using Linked Open Government Data in the TWC LOGD Portal. In David Wood (ed). Linking Government Data, 51-72. Springer New York, 2011.

LINZ. (2009). Spatial information in the New Zealand economy: Realising productivity gains. Land Information New Zealand.

LINZ (2013). Annual Report 2012-13. Land Information New Zealand.

Maali, F., Cyganiak, R., and Peristeras, V. (2010). Enabling interoperability of government data catalogues. Electronic Government, 339-350.

Machado, A. L., and Parente de Oliveira, J. (2011). DIGO: An Open Data Architecture for eGovernment. Paper presented at the Enterprise Distributed Object Computing Conference Workshops (EDOCW), 2011 15th IEEE International.

Myers, M. (1997). Qualitative Research in Information Systems. MIS Quarterly, 21(2), 241-242.

Obama, B. (2009). Transparency and open government. Memorandum for the heads of executive departments and agencies.

Ohm, P. (2010). Broken promises of privacy: Responding to the surprising failure of anonymization. UCLA Law Review, 57, 1701.

Orlikowski, W. J., and Baroudi, J. (1991). Studying Information Technology in Organizations: Research Approaches and Assumptions. Information Systems Research, 2(1), 1-28.

Piotrowski, S. J., and Borry, E. (2010). An analytic framework for open meetings and transparency. Public Administration and Management, 15(1), 138-176. 
Robinson, D., Yu, H., Zeller, W., and Felten, E. (2009). Government data and the invisible hand. Yale Journal of Law and Technology, 11, 160.

Ruppert, E. (2013). Doing the Transparent State: open government data as performance indicators.

Salminen, A., Kallio, J., and Mikkonen, T. (2011). Towards Mobile Multimedia Mashup Ecosystem. Paper presented at the Communications Workshops (ICC), 2011 IEEE International Conference on.

Sieber, R. and Rahemtulla, H. (2010) Model of Public Participation for the Geoweb GIScience 2010 Sixth international conference on Geographic Information Science14-17th September, 2010, Zurich. Available at http://www.giscience2010.org/pdfs/paper_240.pdf

Stecca, M., and Maresca, M. (2010). Mashup Patterns applied to e-Government. Journal of Internet Business(8), 81-108.

Stiglitz, J.E., 2000. The contributions of the economics of information to twentieth century economics. The Quarterly Journal of Economics, 115(4), 1441-1478.

Titah, R., and Barki, H. (2006). E-government adoption and acceptance: A literature review. International Journal of Electronic Government Research (IJEGR), 2(3), 23-57.

van Veenstra, A. F., \& van den Broek, T. A. (2013). Opening Moves-Drivers, Enablers and Barriers of Open Data in a Semi-public Organization. In Electronic Government (pp. 50-61). Springer Berlin Heidelberg.

Wakaruk, A. (2013). Government Information Management in the 21st Century: International PerspectivesPeggyGarvin2011Ashgate PublishingFarnham, Surrey, England; Burlington, VT9781409402060 (232 pp. \$99.95). Government Information Quarterly.

Web Foundation (2013). Open Data Barometer: 2013 Researchers Handbook. Available at http://www.opendataresearch.org/dl/odb2013/OpenDataBarometer-

ResearchHandbookDownloadVersion.pdf

Yang, Z., and Kankanhalli, A. (2013). Innovation in Government Services: The Case of Open Data Grand Successes and Failures in IT. Public and Private Sectors (pp. 644-651): Springer.

Yildiz, M. (2007). E-government research: Reviewing the literature, limitations, and ways forward. Government Information Quarterly, 24(3), 646-665.

Zang, N., Rosson, M. B., and Nasser, V. (2008). Mashups: who? what? why? Paper presented at the CHI'08 extended abstracts on Human factors in computing systems.

Zhang, J., Dawes, S. S., \& Sarkis, J. (2005). Exploring stakeholders' expectations of the benefits and barriers of e-government knowledge sharing.Journal of Enterprise Information Management, 18(5), 548-567. 